\title{
GENETIC SHIFTS IN A YORKSHIRE FOG POPULATION GRAZED BY SHEEP
}

\section{Population Changes Induced by Continuous Hard Grazing}

\author{
R. J. Clements* \\ A gronomy Department, M assey University, Palmerston North
}

H. S. EASTON $\dagger$

Grasslands Division, DSIR, Palmerston N orth

A bstract

Yorkshire fog (Holcus lanatus L. var. 'Massey Basyn') pastures were grazed almost continuously by sheep at high stocking rates for five years. The surviving tiller or paddock population was compared with the original seed population, and with the nine original parents of the variety, by growing the populations as widely-spaced plants and measuring plant size, erectness, leaf size, leaf strength, and heading date. In general, there was a slight genetic shift in the paddock population towards the mean of the parents and away from the mean of the seed population. Differences in the frequencies of esterase isoenzyme bands between the seed and paddock populations provided further evidence that a genetic shift had occurred. However, the magnitude of the shift was small, particularly by comparison with the range of variation observed within each population and between the parents. 'Massey Basyn' is therefore considered to possess an acceptable degree of genetic stability under continuous grazing.

\section{INTRODUCTION}

BECAUSE 'they are heterogeneous, cross-pollinated pasture plant varieties may change genetically in response to natural or artificial selection pressures. In ryegrass varieties, for example, rapid genetic shifts may occur during seed multiplication (Cooper, 1959a; Rumball, 1970), seedling establishment (Charles, 1961), or at some later stage during the life of the pasture. (Brougham et al., 1960). Such shifts will usually improve the adaptation of the plant population to its environment but will not necessarily im-

\footnotetext{
*Present address: Division of Tropical Agronomy, CSIRO, St. Lucia, Qld. 4067, Australia.

†Present address: Station d'Amélioration des Plantes Fourragères, Losignan, Vienne, France.
} 
prove the value of the surviving plants to the grazing animal or to the farmer, because characteristics (e.g., a prostrate growth habit) which favour plant survivall in a given environment may conceivably lead to reduced yield or quality of herbage.

The influence of grazing animals on the development of ecotypes in pasture plants has been discussed by many authors (e.g., Gregor and Sansome, 1927; Jenkin, 1930; Kemp, 1937; Brougham et al., 1960; Bradshaw, 197 1). The available evidence indicates that continuous grazing for many years may lead to profound changes in the genetic structure of pasture plant populatioas in the genera Lolium, Dactylis, Phleum, Poa, and Trifolium, the shift being usually towards smaller, more prostrate plants. In New Zealand, 'Grasslands Manawa' ryegrass (Lolium (perenne $\mathrm{X}$ multiflorum)) has been shown to be particularly unstable, shifting rapidly towards either a perennial or an Italian type depending on the frequency and intensity of grazing (Brougham et al., 1960).

Since its introduction to New Zealand approximately 100 years ago, Yorkshire fog (Holcus lanafus L.) 'has apparently responded markedly to natural selection, as indicated by the distinctive ecoclinal variatioa observed in this species (Basnyat, 1957; Munro, 1961; Jacques, 1962; Jacques and Munro, 1963). However, little is known of the short-term genetic stability of Yorkshire fog populations. 'Massey Basyn', a synthetic variety bred at Massey University by W. A. Jacques, has shown. outstanding potential in pasture trials in New Zealand (Jacques, 1962; Robinson, 1965; Dunbar, 1971 ; Vartha and Clifford, 197 1; Watkin and Robinson, 1974) . Information on the genetic stability of this variety under grazing is needed and is the subject of this series of papers.

\section{EXPERIMENTAL}

The grazing experiment was carried out on a mixture of Kairanga fine sandy loam and Tokomaru silt loam soils at "Tuapaka", a Massey University farm situated $15 \mathrm{~km}$ from Palmerston North. The spaced plant experiment was conducted et Massey University, Palmerston North, on a. silt loam of the Ohakea series; The average annual rainfall at both sites is approximately $1016 \mathrm{~mm}$ (40 in.).

In- April 1966, a seeds mixture consisting of Yorkshire fog (syn. 1 seed of Holcus lanatus L. var. 'Massey Basyn') at approximately $10 \mathrm{~kg} / \mathrm{ha}$ and white clover (Trifolium repens l;. var. 'Grasstands Huia') at $3.4 \mathrm{~kg} / \mathrm{ha}$ was sown in two paddocks each 
0.27 ha in area. After an initial dressing of c. $250 \mathrm{~kg} / \mathrm{ha}$ at sowing, $30 \%$ potassic superphosphate was applied to the pastures each year in the autumn and spring at an annual application rate of $630 \mathrm{~kg} / \mathrm{ha}$. During their first year of growth, the paddocks were rotationally grazed by sheep to produce a dense, vigorous pasture. From April 1967 until the end of March 1969, each paddock was set-stocked with nine Romney wethers, providing a stocking rate of 33.3 sheep/ha (13.5 sheep/ac). From April 1969 until early December 1969, seven Romney ewes, together with their lambs from spring onwards, were set-stocked in each paddock. During the following eighteen months the paddocks were subjected either to continuous or to frequent rotational grazing. At no time were the paddocks allowed to go to seed (although occasional seedheads were observed in each summer) and the consistently high stocking rate's kept the pastures short and dense 'throughout the entire grazing period of more than five years. At the time of sampling, the pastures were 1 to $2 \mathrm{~cm}$ in 'height. From the time of sampling, caged areas were allowed to grow for 45 days ( 15 to $20 \mathrm{~cm}$ in height), at which time the "pastures consisted of $60 \%$ Yorkshire fog, 10\% white clover and $30 \%$ other species (mainly grasses) on a dry weight basis. Details of the paddocks and of the performance of the animals grazing them may be found elsewhere (Watkin and Robinson, 1974).

On August 20, 1971, a $5 \mathrm{~cm}$ diameter core sampler was used to collect 150 pasture cores at $30 \mathrm{~cm}$ intervals along a diagonal transect in each paddock, keeping well clear of the fences. Ramets were subsequently dissected from these samples, each from a different core, and planted in deep seedling boxes in a glasshouse. At the same time, individual tillers were dissected from the nine parents of 'Massey Basyn' Yorkshire fog, which had been maintained as spaced plants on the University campus. These tillers were also planted in the glasshouse. A sample of syn. 1 seed of 'Massey Basyn' was germinated in the same sand/soil mixture and seedlings were subsequently transferred to a third group of boxes in the glasshouse. During the following weeks the plants were cut back several times and maintained under favourable conditions. On November 9, 197 1, the three populations (i.e., the paddock population, the parents, and the seed population) were transplanted to the field at $75 \times 75 \mathrm{~cm}$ spacings, each population being represented by two adjoining 5-plant rows in each of 20 replicate's in a randomized block design, giving a total of 600 plants. Each of the nine parents was included in each replicate 
of the parent population, the remaining position being filled by a guard plant which was subsequently excluded from the statistical analysis.

The plants were grazed by sheep on two occasions during the summer and early autumn, and kept free of weeds. On May 8, 1972, plants were scored for erectness on a 1 (prostrate) to 3 (erect) scale by four observers, two of whom were unfamiliar with the experiment. Plant size was scored on a 1 (small) to 5 (large) scale by three \&servers. The subsequent statistical analyses of erectness and size were based on the scores summed over observers. On May 9, 1972, the youngest fully-expanded leaf on each of four tillers from the centre of each plant was taken, and areas of these leaves were measured using a photoelectric leaf area meter (Murata and Hayashi, 1967). On May 10-12, 1972 , leaf strength was measured on one carefully selected leaf per plant, using the apparatus and technique of Evans (1967a). Particular care was taken to select young, 'healthy, completely expanded leaves from the centre of each plant, and to measure leaf strength as soon as possible after sampling.

On June 6, 1972, several carefully selected leaves were again taken from a random sample of 50 plants from each of the paddock and seed populations, and from several replicates of the parent population, and stored in plastic bags at $-20^{\circ} \mathrm{C}$. Esterase isoenzyme bands were subsequently examined in this material by means of polyacrylamide gel electrophoresis, using equipment and techniques similar to those described by Reid and Bieleski (1968). The stain used for the esterases was prepared by adding $20 \mathrm{mg}$ naphthylacetate in $2 \mathrm{ml}$ acetone to $100 \mathrm{ml} 0.08 \mathrm{M}$ tris chloride buffer ( $\mathrm{pH} \mathrm{6.5)}$, followed by the addition of $100 \mathrm{mg}$ fast garnet. Preliminary investigations showed that freezing the tissues had no effect on the presence or relative positions of the esterase bands on the gel, though it did reduce the intensity of staining.

The plants were last grazed on June 7-9, 1972, after which they were allowed to grow without defoliation until the date of heading of each plant was recorded. Heading was defined as the stage at which the tips of the emerging inflorescences were visible on at least four tillers on a plant, and heading date was measured in days after October 31, 1972. Heading date is under close genetic control in pasture plants (e.g., Cooper, 1959b; McWilliam and Latter, 1970) and is therefore a useful diagnostic character for detecting genetic differences between populations. 

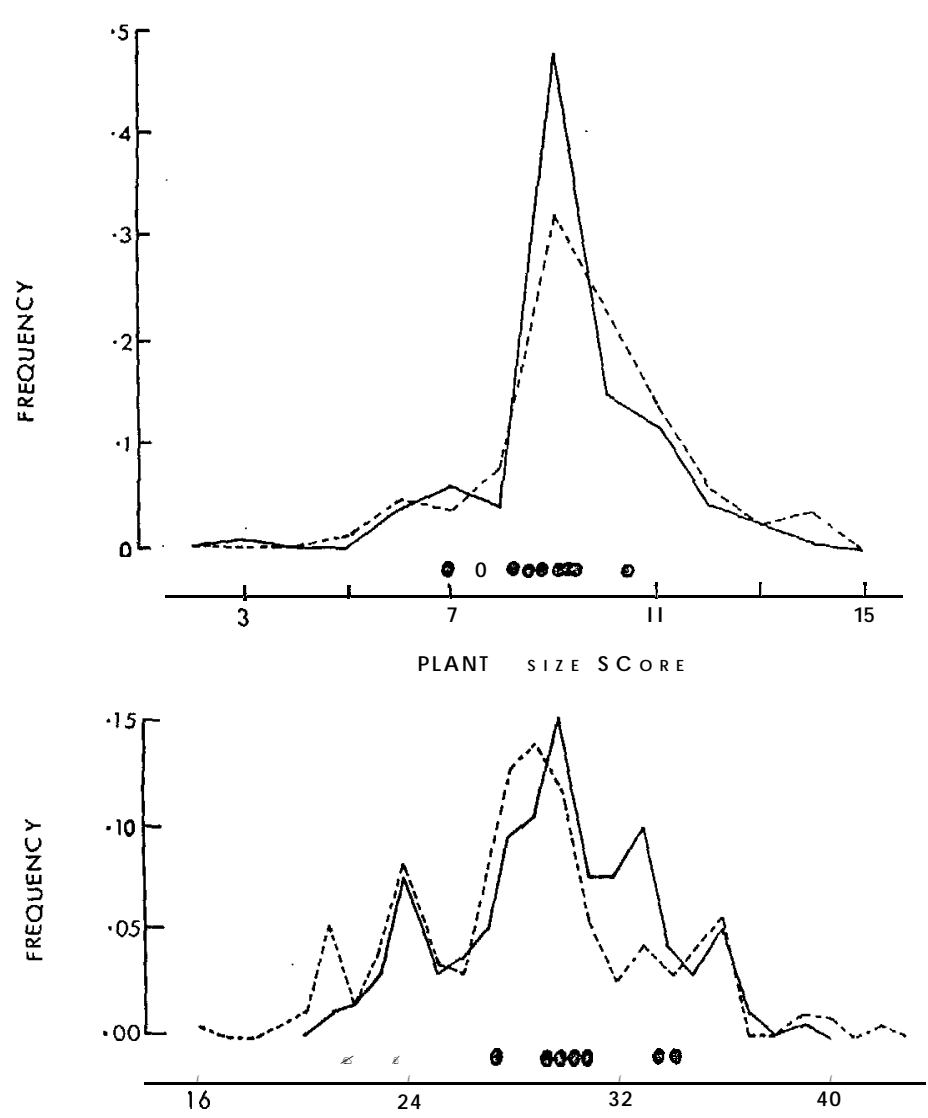

HEADING DATE (DAYS AFTER OCT. 31)

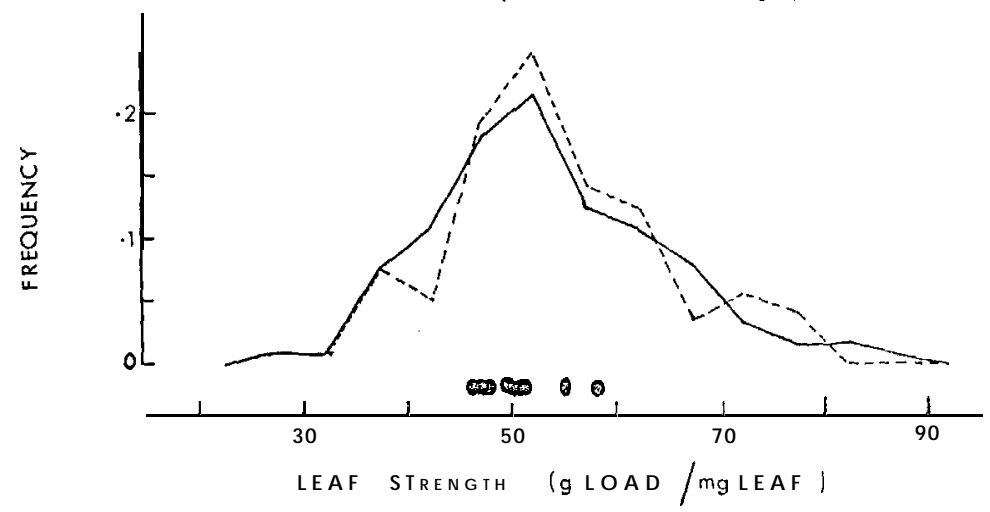



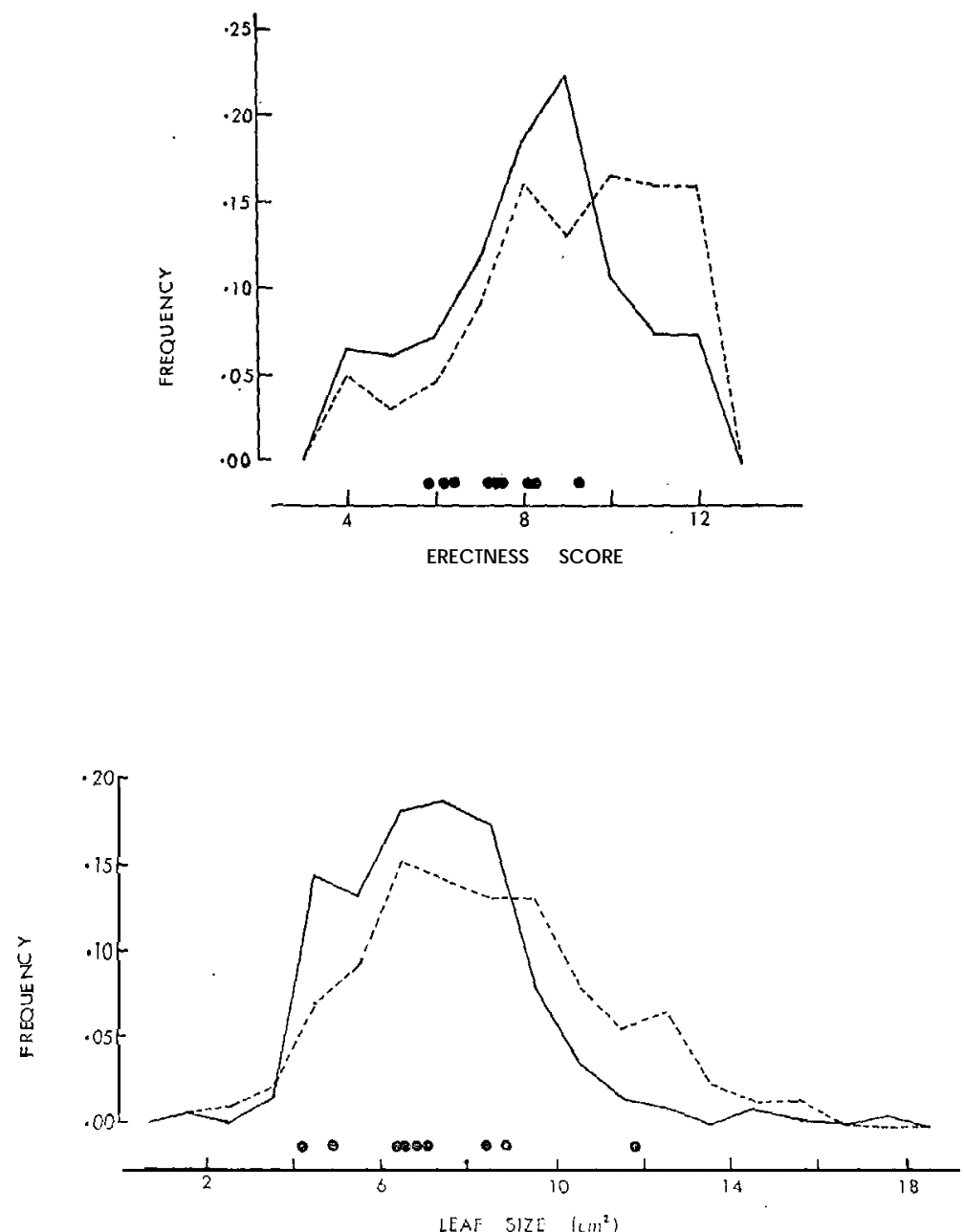

FIG. 1: Distribution of values of individual plants from the paddock

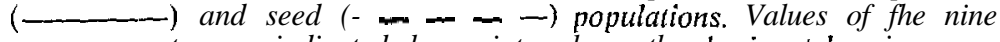
parents are indicated by points along the horizontal axis. 
TABLE 1: POPULATION MEAN VALUES

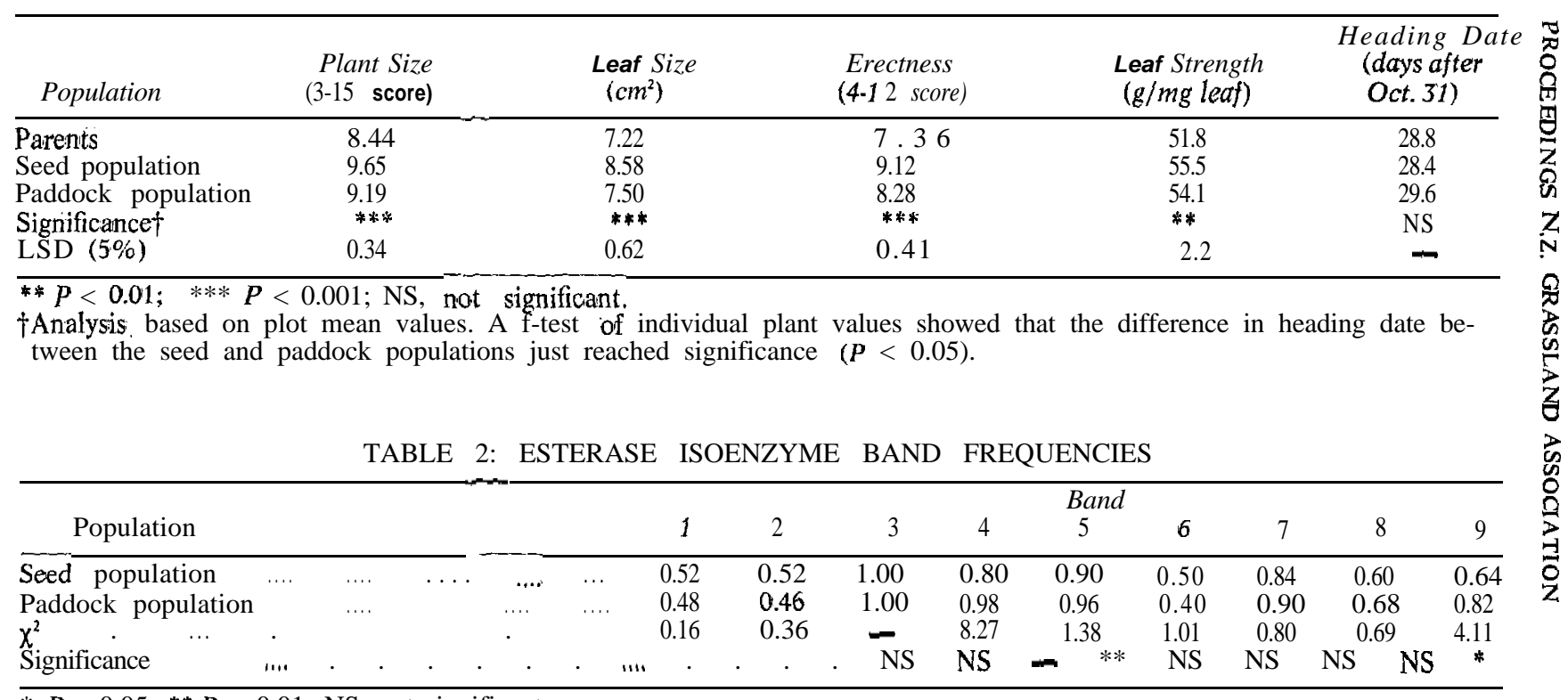

$* \boldsymbol{P}<0.05 ; * * \boldsymbol{P}<0.01 ;$ NS, not significant. 


\section{RESULTS AND DISCUSSIONS}

The population mean values, and the distributions of values of individual plants for each of the characters measured, are shown in Table 1 and Fig. 1, respectively. Plants from the seed population were larger and more erect than the parents, with relatively large, strong leaves. Plants from the paddock population were intermediate in size and erectness, with a mean leaf strength similar to that of the seed population and a mean leaf size similar to that of the parents. The analysis of variance of plot means showed no significant differences in mean heading date between the populations. However, there was no significant variation due to replicates for this character, and a f-test based on the individual plant values indicated that the difference: between the seed and paddock populations was significant $(P<0.05)$.

Although effects such as plant age cannot be discounted as contributing to the differences between the population's, the significant variation in the frequencies of two of the nine esterase bands examined (Table 2) provides further evidence of real genetic differences between populations, since such isoenzyme bands are known to be under close genetic control (Scandalios, 1969). All bands which occurred in the paddock and seed populations were also observed in the parents, but no one parent possessed all of the bands,

Although the populations therefore differed significantly with respect to all five quantitative characters studied, the differences were small by comparison with the range of variation within each population (Fig. 1). Assuming that at least some of this variation, was genetic in origin (as suggested by the highly significant differences among the parents for each character), the results indicate that any genetic shifts in the paddock population were small compared with the changes that could have occurred, However, the direction of the shift in the paddock population, towards

a more prostrate, small-leafed plant, is in agreement with the results of other workers (e.g., Brougham et al., 1960, with Lolium) .

The small and barely significant difference in mean heading date between the seed and paddock populations suggests that this character was not closely associated with survival under grazing. This slight shift is in agreement with the results of Hayward $(1970,1972)$ with Lolium perenne, where a weak shift towards later heading after 2 years' intensive grazing appeared to be indicated. 
The data do not indicate a shift in lea4 strength in the paddock population. The significant difference that occurred was between the parents and the two progeny populations. Since Edmond (1960, 1964) and Evans (1967b) have suggested low leaf strength as one possible mason for the poor resistance of Yorkshire fog to trampling by sheep, this result was unexpected, particularly in view of the variation in leaf strength between the parents and within the progeny populations. It is possible that there may have been real differences between the two progeny populations not detected in this experiment - e.g., due to the choice of scale or to the time of year (Evans, 1967a). However, a possible explanation for the lack of shift was a positive genotypic correlation $\left(r_{\mathrm{g}}=0.42\right)$ between erectness and leaf strength among the parents. Assuming that such a genetic correlation existed among the progeny, a selective force favouring prostrate plants might have confounded weaker selection for strong-leafed plants. If this was so, the possession of a prostrate growth habit must have been more important to plant survival than the possession of strong leaves.

The results of this experiment do not provide unequivocal evidence that 'Massey Basyn' is genetically stable. Only one grazing system was employed, and the variety may well be better adapted to continuous close grazing than to lax or rotational grazing. Differences in the ages of the three populations may have affected plant vigour and leaf size, and may even conceivably have influenced the isoenzyme banding patterns. Larger genetic shifts might occur over a longer time period. Hence, although it is considered that the present experiment provides strong circumstantial evidence of stability under close grazing, experiments are now in progress to examine the stability of 'Massey Basyn' under contrasting management systems.

\section{ACKNOWLEDGEMENTS}

We thank Professor B. R. Watkin (Agronomy Department, Massey University), who kindly allowed us to sample the Yorkshire fog paddocks in his experiments at "Tuapaka", and who provided details of the history of the paddocks. Thanks are also due to Dr M. D. Ross (Grasslands Division, DSIR) and R. B. Broadhurst (Applied Biochemistry Division, DSIR) for their advice on polyacrylamide gel electrophoresis and to Dr P. S. Evans (Grasslands Division, DSIR) for advice on the measurement of leaf strength. P. Sanders (Massey University) assisted in the measurement of heading dates, and Professor Watkin and G. 0. 
Edmeades (Agronomy Department, Massey University) provided observations on plant size and erectness.

\section{REFERENCES}

Basnyat, N. B., 1957: M.Agr.Sc. thesis, Massey University.

Bradshaw, A. D., 1971: In editor), Blackwell Scientific Publications, Oxford: p. 20.

(R. Creed,

Brougham, R. W.; Glenday,, A. C.; Fejer, S. O., 1960: N.Z. $/ l$ agric. Res. 3: 442 .

Charles, A. H., 1961: J. Br. Grassld Soc., 16: 69.

Cooper, J. P., 1959a: J. Br. Grass/d Soc., 14; 183.

1959b: Heredity, 13: 445.

Dunbar, G. A., 1971: Proc. N.Z. Ecol. Soc. 18: 48.

Edmond, D. B., 1960: Proc. N.Z. G rassld Ass., 22: 111 1964: N.Z. JI agric. Res., 7: 1.

Evans, P. S., 1967a: J. agric. Sci., Camb., 69: 171. 1967b: J. agric. Sci., Camb., 69: 175.

Gregor, J. W.; Sansome, F. W., 1927: I. Genet., 17: 349.

Hayward, M. D., 1970: Heredity, 25: 441-7. 1972: Heredity, 29: 375-9.

Jacques, W. A., 1962: Proc. N.Z. GrassId Ass., 24: 139.

Jacques, W. A.; Munro, J. M. M., 1963: In Advancing Frontiers of Plant Sciences (L. Chandra, editor), Institute for the Advancement of Science and Culture, New Delhi: vol. 4: 27.

Jenkin, T. J., 1930: Welsh J. Agric., 6: 140.

Kemp, W. B., 1937: J. Hered., 28: 329.

McWilliam, J. R.; Latter, B. D. H., 1970: Theoret. Appl. Genet., 40: 63. Munro, J. M. M., 1961: M.Agr.Sc. thesis, Massey University.

Murata, Y.; 'Hayashi, K., 1967: Proc. Crop Sci. Soc Japan, 36: 463.

Reid, M. S.; Bieleski, R. L., 1968: Anal. Biochem., 22: 374.

Robinson, G. S., 1965: Sheepfmg A., 1965: 57. Massey University.

Rumball, W., 1970: N.Z. Il agric. Res., 13: 605.

Scandalios, J. G., 1969: Biochem. Genet., 3: 37.

Vartha, E. W.; Clifford, P. T., 1971: N.Z. Tussock Grasslds Mountain Lands Inst. Rev., 22: 55.

Watkin, B. R.; Robinson, G. S., 1974: Proc. N.Z. GrassId Ass., 35 (2) : 27883. 